\title{
Resilient Schedule Coordination for a Bus Transit Corridor
}

\author{
Xiongfei Lai, ${ }^{1}$ Jing Teng $\mathbb{D}^{1},{ }^{1}$ Paul Schonfeld, ${ }^{2}$ and Lu Ling ${ }^{3}$ \\ ${ }^{1}$ The Key Laboratory of Road and Traffic Engineering of the Ministry of Education, Tongji University, 4800 Cao'an Road, \\ Shanghai, China \\ ${ }^{2}$ Department of Civil and Environmental Engineering, University of Maryland, 1173 Glenn L. Martin Hall, College Park, \\ MD 20742, USA \\ ${ }^{3}$ Lyles School of Civil Engineering, Purdue University, 550 Stadium Mall Drive, West Lafayette, IN 47906, USA
}

Correspondence should be addressed to Jing Teng; tengjing@tongji.edu.cn

Received 7 February 2020; Revised 17 May 2020; Accepted 26 May 2020; Published 15 June 2020

Academic Editor: Yu Jiang

Copyright (c) 2020 Xiongfei Lai et al. This is an open access article distributed under the Creative Commons Attribution License, which permits unrestricted use, distribution, and reproduction in any medium, provided the original work is properly cited.

Providing convenient transit services at reasonable cost is important for transit agencies. Timed transfers that schedule vehicles from various routes to arrive at some transfer stations simultaneously (or nearly so) can significantly reduce wait times in transit networks, while stochastic passenger flows and complex operating environments may reduce this improvement. Although transit priority methods have been applied in some high-density cities, operating delays may cause priority failures. This paper proposes a resilient schedule coordination method for a bus transit corridor, which analyzes link travel time, passenger loading delay, and priority signal intersection delay. It maximizes resilience based on realistic passenger flow volume, whether or not transit priority is provided. The data accuracy and result validity are improved with automatically collected data from multiple bus routes in a corridor. The Yan'an Road transit corridor in Shanghai is used as a case study. The results show that the proposed method can increase the system resilience by balancing operation cost and passenger-based cost. It also provides a guideline for realistic bus schedule coordination.

\section{Introduction}

Providing convenient transit services for passengers at reasonable total cost is one of the main purposes of transit agencies. Bus routes operate under high pressure in China because of large passenger flow and complex road conditions, so a resilient bus system is needed.

As urban areas expand, transit networks become more complex. A rail transit network may serve as a backbone network, while bus routes connect and feed the rail transit network, serve as shuttle systems, and provide door-to-door transit services. In metropolitan areas, transfers among transit routes are needed because fixed-route buses cannot economically provide direct service among all origins and destinations. The potential value of schedule coordination is that user waiting time may be reduced at transfer stations if vehicles from different routes can arrive at transfer stations simultaneously (or nearly so). The passengers can then transfer quickly among vehicles that stop briefly near one another. A schedule coordination system can greatly reduce passenger wait times at transfer stations but cannot completely eliminate them in a system with probabilistic running times and delays.

Metropolitan areas have complex traffic conditions as well as stochastic transit demand, which may force some vehicles off their schedules and greatly increase the difficulty of achieving coordinated timed transfers. Slack time, which is a buffer parameter, should be included and optimized in schedules in order to reduce the probability of missed connections for passengers at transfer stations. Additional slack time increases operation cost but also increases transfer reliability by countering some travel time randomness $[1,2]$. For each bus route, it is important to optimize the headway, which influences the vehicle operating cost and passenger waiting time. Therefore, a method is proposed here for jointly optimizing bus headways and slack times in an integrated bus system with multiple transfer stations in a transit corridor. 
Schedule coordination has been well researched in different environments, while analysis and optimization of coordination performance in changing transit environments are rarely researched. Resilience reflects how a transit system is influenced by changes in its environment and how it recovers from such change. This paper proposes a method for schedule coordination considering transit system resilience. This method increases system resilience while balancing operator and user costs. This optimization is based on real-world environments, involving passenger flow fluctuations and travel times based on traffic conditions.

\section{Literature Review}

2.1. Schedule Coordination. Bus schedule coordination has been researched over decades. Many models have been developed for optimizing bus systems while considering transfer passengers. Among them, Rapp and Gehner [1] first developed a four-stage interactive computerized system for transfer optimization, with minimum total transfer waiting time as its objective function. Then, service quality has been considered by Andréasson [3] and Abkowitz et al. [4]. Since schedule coordination is difficult to solve analytically, a computerized tool has been developed for solving it as early as 1992 [5]. In 2001, Daganzo [6] generated a synchronized timetable for a given network by maximizing the number of simultaneous bus arrivals at the transfer nodes of the network. Since then, many extensions have been presented for solving this problem more realistically [7-10]. Relevant studies have explored whether timed transfers are appropriate for large networks with decentralized transfers [11] and how slack times can be optimized at transfer points with simple deterministic models [12] or simulation models [4]. Since passenger demand and vehicle travel times are stochastic, researchers developed probabilistic models for this problem [11]. Being limited by data sources and computational performance, research in this period mainly focused on simplifying and modeling schedule coordination in given numerical cases.

In recent years, researchers have researched this problem with more detailed and realistic methods. Ting and Schonfeld [13] proposed a schedule coordination method for a multiple hub transit network, which is more challenging than that for single hub networks. As noted in [14], the bus transit network planning problem can be presented as a sequence of four main phases, in which bus timetable preparation is the second step. Some works focus on jointly optimizing this step with vehicle scheduling [15-17]. Wu et al. presented a comprehensive review of multiobjective resynchronizing of a bus timetable, involving model and solution [18]. With real-time information, transit agencies can now predict travel time with high accuracy, thus enabling reliable and dynamic timetable optimization to be combined with bus coordination [19, 20]. Data driven modeling, as well as sufficient computational ability, makes schedule coordination more realistic and readier for application.

A rail transit network typically has a backbone role in an urban public transport system, while bus routes are usually used to connect rail transit stations with the passengers' travel origins and destinations. Multimode transit schedule coordination is well researched $[21,22]$. A transport corridor is a generally linear area defined and served by one or more modes of transportation such as highways, railroads, or public transit, which share a common course. Transfers occur mainly at transfer stations where multiple routes converge. Hence, studies have been conducted to characterize different kinds of transfers and then optimize them [23-25].

Algorithms for solving this problem have been widely researched. Ibarra-Rojas and Rios-Solis have proved that the synchronized timetabling problem is NP hard. They have proposed a multistart iterated local search algorithm and a mixed integer programming method [9]. However, heuristic methods are more usually used to quickly produce timetables. Ibarra-Rojas et al. extended the heuristics from their previous work to solve a multiperiod case [26]. Other methods, including a genetic algorithm [27, 28], mixed integer programming [9], and tabu search [17], have also been used for solving this problem.

Although previous studies considered travel times when coordinating schedules, these studies usually assumed stable travel times. However, different components including the links, the stations, and even the transit priority operations may be influenced by different factors and have different impact on travel time estimation [29, 30]. For example, link travel times may be influenced by traffic, while dwell times may mainly be affected by passenger flows. With the development of advanced public transportation technologies, such as automatic vehicle location (AVL) and automatic fare collection (AFC) systems, more realistic situations with detailed travel times should be considered for schedule coordination.

2.2. Resilience. Resilience in transportation research is divided into two parts: elasticity analysis [31, 32] from the economic aspect and system resilience or vulnerability [33-35] from the physical aspect. In 1992, Wakabayashi and Iida proposed the concept of overall resilience of the system and introduced system resilience to traffic network analysis [36]. After 2000, researchers analyzed the resilience of transport system for two main cases: the recovery ability under foreseeable events (e.g., large-scale passenger flows and changes of road environment) $[37,38]$ or unforeseeable events (e.g., hurricanes, snowstorms, and earthquakes) $[39,40]$. Compared with foreseeable system changes, unforeseeable changes are more serious and yield slower recoveries. In this field, researchers consider the change intensity and recovery ability of different traffic modes, such as rail transit compared with taxi. In addition, the study of combined resilience and vulnerability is also a hot topic. For example, the recovery cost of the system can be analyzed through the critical values [41, 42]. In transport system resilience, the main research objective is the system's restorability, which contains transportation capacity and transportation time. 


\section{Methodology}

The proposed method analyzes a transit corridor containing a multimode bus system connecting a rail transit station. Such cases are common in real-world operations since bus routes are usually used to connect rail transit stations with the passengers' travel origins and destinations. The following assumptions are made in this study:

(1) The network of transit routes is predetermined and buses stop at every station along their routes

(2) It is assumed to be independent of transit service quality, deterministic, and uniformly distributed over time during the specified time period

(3) Preplanned transfer coordination is assumed under a no-hold policy

(4) The capacity of each bus station is unlimited

For coordinated operation, we search for optimized headways that are integer multiples of the base cycle in order to increase the possibility of immediate connections at transfer stations. To do so, schedules for all the routes have to be optimized jointly.

In the next sections total system costs with timed transfers are formulated. Then the station delay and signal priority intersection delay are checked to ensure that these optimized headways and slack times for each bus routes are reliable. Both uncoordinated and coordinated operations include nontransfer and transfer costs. Nontransfer costs include vehicle operating cost and passenger waiting cost. Transfer costs include slack-time cost, missed-connection cost, and dispatching-delay cost. Analytic solutions for uncoordinated operation are obtained. A heuristic algorithm for coordinated operation is also presented. All the results for a real-world case are verified by comparisons with the previous study of Ting and Schonfeld [13].

Symbols used in this paper are shown in Table 1. Predetermined parameters have certain baselines, which come from "TCRP 165: Transit Capacity and Quality of Service Manual" [43] and field research by the Shanghai Science and Technology Committee (unpublished reports):

3.1. Uncoordinated Operation. This paper aims to optimize bus headway in a multimode transit system. The rail transit is a part of input of bus passenger flow volume. As we can get passengers' location by both smart card data and bus's GPS data, the passenger volume can be acquired as follows:

(1) Passengers transferring from rail transit to bus can be identified from 2 consecutive smart card swiping records (rail transit to bus) in one time period (from 6:00 am to $12: 00 \mathrm{pm}$ )

(2) Passengers transferring from one bus line to another can be identified as 2 consecutive smart card swiping records (bus line 1 to bus line 2) in 1 time period (from 6:00 am to 12:00 pm)

(3) Other passengers can be identified as smart card swiping record
In uncoordinated operation, the objective is to minimize the total system cost by optimizing the headway independently for each route. However, many factors, such as road delay, intersection delay, and station delay, can affect bus travel time $[29,30]$. With real-time information, transit agencies can now predict travel time with high accuracy $[29,30,44]$. The round-trip time, $T_{k}$, of route $k$ is the sum of travel times on all the links of route $k$. The travel time can be divided into three parts: link travel time, dwell time at stations $\left(T_{0}+T_{b}\right)$, and delay at signal priority intersections. The travel time can be expressed as

$$
T_{k}=\sum_{i \in A(k)} E\left(t_{i}\right)=\sum_{r \in A(k)} E\left(t_{r}\right)+\left(T_{0}+T_{b}\right)+\vartheta T_{\text {sig. }} .
$$

In reality, since some bus routes have long headways, the travel time data are insufficient for analysis. Multiple routes' data can be gathered to obtain $E\left(t_{r}\right)$.

Figures 1 and 2 show a transit corridor with three bus routes in Shanghai. While the planned headway of route 936 is 30 minutes, it only operates 30 times a day, so link travel time data are insufficient. However, when we combine these three routes, we collect over 300 bus round trips per day. The detailed method for combining travel times of each route in the same corridor can be found in [45].

The vehicle size used here and the linear function of vehicle operating cost proposed by Jansson [46] are as follows:

$$
\begin{gathered}
S_{k}=\frac{L_{k} Q_{k} h_{k}}{l_{k}}, \\
B_{k}=a_{k}+b_{k} S_{k} .
\end{gathered}
$$

In (2), the demand $Q_{k}$ is multiplied by a maximum load factor $L_{k}$ to allow for more-than-expected passengers/bus.

The operating cost of route $k$ is the product of the needed fleet size $T_{k} / h_{k}$ and the unit operating cost. The total operating cost is

$$
C_{o}=\sum_{k} \frac{B_{k} T_{k}}{h_{k}}=\sum_{k}\left(\frac{a_{k} T_{k}}{h_{k}}+\frac{L_{k} b_{k} Q_{k} T_{k}}{l_{k}}\right) .
$$

According to the stochastic process for passenger arrivals at stops (randomly and uniformly over time), the waiting time may be estimated as that by Welding [47] or Osuna and Newell [48]:

$$
w_{k}=\frac{E\left(h_{k}\right)}{2}\left(1+\frac{\sigma_{k}^{2}}{\left[E\left(h_{k}\right)\right]^{2}}\right) .
$$

The waiting cost is a product of waiting time $w_{k}$, unit waiting cost $\mu$, and passenger value $Q_{k}$ :

$$
C_{w}=\sum_{k} \mu Q_{k} w_{k}
$$

When bus routes operate independently, the transfer waiting time is equal to $w_{k}$, so $C_{f}$ can be formulated as 
TAble 1: Notation.

\begin{tabular}{|c|c|c|}
\hline Symbol & Meaning & Baseline value \\
\hline$A(k)$ & Set of links of route $k$ & - \\
\hline$a_{k}$ & Fixed vehicle operating cost of route $k(\mathrm{RMB} / \mathrm{min})$ & 100 \\
\hline$B_{k}$ & Unit vehicle operating cost (RMB/vehicle-min) & 4.0 \\
\hline$b_{k}^{n}$ & Variable vehicle operating cost of route $k(\mathrm{RMB} /$ seat-min) & 0.2 \\
\hline$C_{o}$ & Operating cost of route $k(\mathrm{RMB} / \mathrm{min})$ & - \\
\hline$C_{w}$ & Total waiting cost $(\mathrm{RMB} / \mathrm{min})$ & - \\
\hline$C_{b}$ & Total boarding delay cost $(\mathrm{RMB} / \mathrm{min})$ & - \\
\hline$C_{f}$ & Total transfer cost $(\mathrm{RMB} / \mathrm{min})$ & - \\
\hline$C_{p}$ & Intercycle delay cost (RMB/min) & - \\
\hline$C_{m}^{P}$ & Missed-connection cost (RMB/min) & - \\
\hline$C_{d}$ & Dispatching-delay cost (RMB/min) & - \\
\hline$C_{s}$ & Slack-time cost $(\mathrm{RMB} / \mathrm{min})$ & - \\
\hline$C_{T}$ & Total cost $(\mathrm{RMB} / \mathrm{min})$ in time period & - \\
\hline$C_{T 0}$ & The lowest total cost $(\mathrm{RMB} / \mathrm{min})$ in time period & - \\
\hline$C_{\text {sig }}$ & Delay cost at signal priority intersection $(\mathrm{RMB} / \mathrm{min})$ & - \\
\hline$D_{m k}$ & Number of passengers already on board at transfer center $m$ on route $k$ (passengers $/ \mathrm{min}$ ) & - \\
\hline$E\left(h_{k}\right)$ & Expected value of route $k$ headway $(\min )$ & - \\
\hline$E\left(t_{i}\right)$ & Expected travel time on link $I$ (min) & - \\
\hline$E\left(t_{r i}\right)$ & Expected running time on link $i(\min )$ & - \\
\hline$F_{m k}$ & Transfer demand from other routes to route $k$ at transfer center $m$ (passengers $/ \mathrm{min}$ ) & - \\
\hline$f\left(t_{k}\right)$ & Probability density function of arrival time on route $k$ & - \\
\hline$g_{j k}$ & Greatest common divisor of $\beta_{j}$ and $\beta_{k}$ & - \\
\hline$h_{k}$ & Headway of route $k(\min )$ & - \\
\hline$L_{\mathrm{k}}$ & Maximum load factor on route $k$ & - \\
\hline$l_{k}$ & Load factor on route $k$ & - \\
\hline$N_{k}$ & Frequency of missing signal priority (buses/hour) & - \\
\hline$Q_{k}$ & Demand of route $k$ (passengers/min) & - \\
\hline$q_{j k}$ & Transfer demand from route $j$ to $k$ (passenger/min) & - \\
\hline$R_{k}$ & Total transfer demand to route $k$ (passenger/min) & - \\
\hline$S_{k}$ & Vehicle size on route $\mathrm{k}$ & - \\
\hline$T_{k}$ & Round-trip time $(\mathrm{min})$ & - \\
\hline$s_{m k}$ & Slack time at station $m$ on route $k(\mathrm{~min})$ & - \\
\hline$T_{0}$ & Scheduled passenger loading time per station (min) & - \\
\hline$T_{b}$ & Extra passenger loading time per station (min) & - \\
\hline$T_{i}$ & Vehicle delay at signal priority intersection ( $\mathrm{min}$ ) & - \\
\hline$T_{m}$ & Passenger loading time $(\min )$ & - \\
\hline$T_{n}$ & Passenger alighting time (min) & - \\
\hline$T$ & Traffic signal time cycle (min) & - \\
\hline$T_{x}$ & Link travel time $(\mathrm{min})$ & - \\
\hline$T_{\text {sig }}$ & Delay time at signal priority intersection (min) & - \\
\hline$T_{G}$ & Green light time in a traffic signal cycle (min) & - \\
\hline$T_{P}$ & Duration of time period $(\mathrm{min})$ & - \\
\hline$v$ & In-vehicle value of time (RMB/passenger-min) & - \\
\hline$y$ & Base cycle $(\mathrm{min})$; value is $1 \mathrm{~min}$, the same as the minimum value of headway in a rail station & - \\
\hline$z_{j k}$ & The transfer waiting times between connecting routes $j$ and $k(\mathrm{RMB})$ & - \\
\hline$\vartheta^{\prime n}$ & Signal priority indicator ( $=1$ if signal priority provided and 0 otherwise) & - \\
\hline$\sigma_{k}^{2}$ & Variance of headway on route $k\left(\min ^{2}\right)$ & - \\
\hline$\mu_{1}$ & Unit passenger waiting cost (RMB/passenger-min; baseline value is $1.5 \mathrm{RMB} /$ passenger-min) & 1.5 \\
\hline$\mu_{2}$ & $\begin{array}{c}\text { Unit passenger waiting cost ( } \mathrm{RMB} / \text { passenger-min; baseline value is } 5.0 \mathrm{RMB} / \text { passenger-min) from boarding } \\
\text { delay }\end{array}$ & 5.0 \\
\hline$\mu_{3}$ & Unit passenger waiting cost (RMB/passenger-min) from missing signal priority intersections & 10,000 \\
\hline$\alpha$ & Unit passenger loading time (min/passenger) & 0.1 \\
\hline$\beta$ & Unit passenger alighting time (min/passenger) & 0.05 \\
\hline$\beta_{j}$ & Integer multiples of the base cycle & - \\
\hline$\delta_{m k}$ & $\delta_{m k}=1$ if transfer station $m$ is on route $k$ and 0 otherwise & - \\
\hline
\end{tabular}




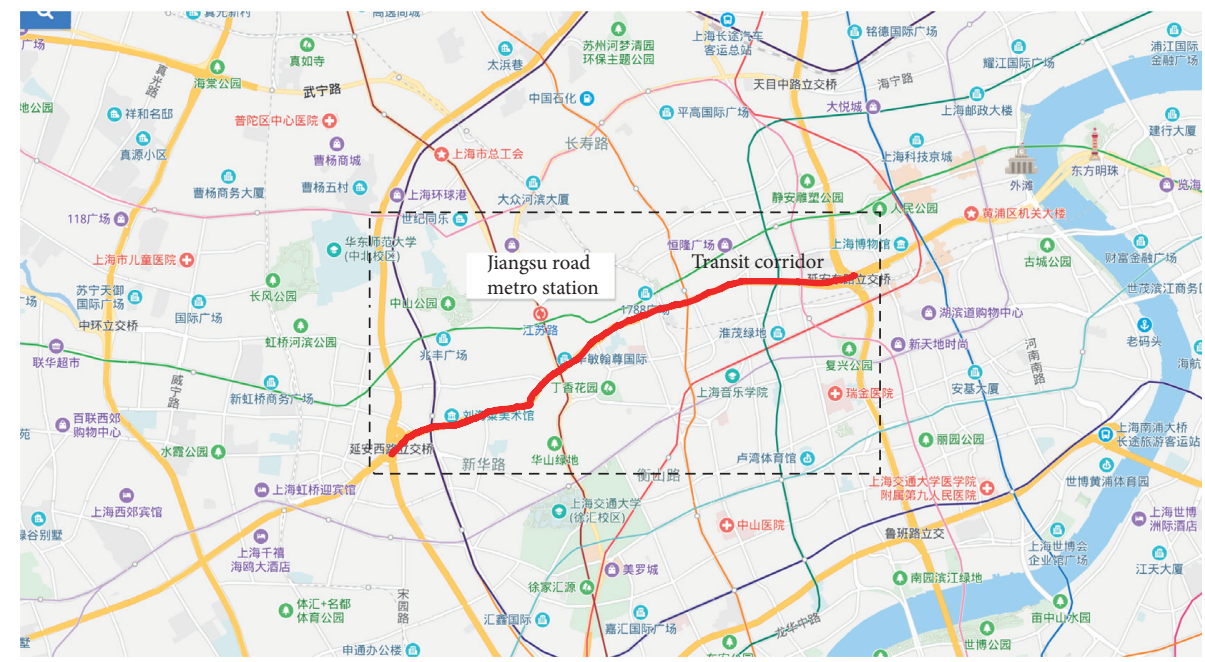

Figure 1: Layout of the transit corridor in Shanghai.

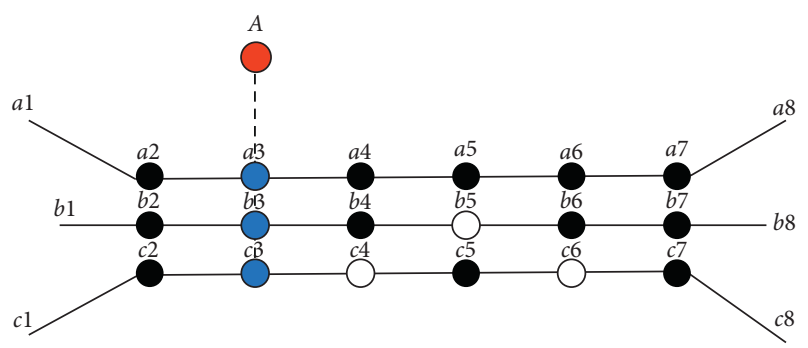

Bus station

Metro station

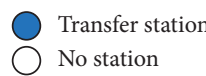

FIGURE 2: Initial bus routes layout.

$$
C_{f}=\sum_{j} \sum_{\substack{k \\ k \neq j}} \mu q_{j k} w_{k}=\sum_{j} \sum_{\substack{k \\ k \neq j}} \mu R_{k}\left[\frac{E\left(h_{k}\right)}{2}\left(1+\frac{\sigma_{k}^{2}}{\left[E\left(h_{k}\right)\right]^{2}}\right)\right] .
$$

When the passenger flows per bus increase, bus dwell times at stops also increase. The stopping delay can be expressed as follows:

$$
\begin{aligned}
T_{m} & = \begin{cases}\alpha m_{k}-T_{0}, & \alpha m_{k} \geq T_{0}, \\
0, & \text { otherwise, }\end{cases} \\
T_{n} & = \begin{cases}\beta n_{k}-T_{0}, & \beta n_{k} \geq T_{0}, \\
0, & \text { otherwise, }\end{cases} \\
C_{b} & =\sum_{k} \mu_{2} Q_{k} T_{b}=\mu_{2}\left(T_{m}+T_{n}\right) .
\end{aligned}
$$

Although the bus wait time at intersections is included in $E\left(t_{r}\right)$, there should be no delay at intersections with signal priority. Priorities including bus lane along with signal priority have been applied on particular bus routes to improve their operation efficiency and reliability. However, since priorities are only given in a certain period during a signal circle, when delays exceed this certain period, buses may miss the signal priority. If buses operate on exclusive lanes, these delays are mainly caused by boarding delay at stations. Thus, signal priority missing cost is introduced as follows:

$$
C_{\text {sig }}=\sum_{k} \mu_{3} Q_{k} T_{\text {sig }}= \begin{cases}\sum_{k} \mu_{3} Q_{k} \frac{T-T_{G}}{2}, & T_{b} \geq T_{G} \\ 0, & \text { otherwise. }\end{cases}
$$

During the optimization process, $\mu_{3}$ is set extremely high to avoid missing signal priority.

To sum up, the total cost is

$$
C_{T}=C_{o}+C_{w}+C_{f}
$$

In this paper, the goal of the optimization process is to maximize resilience in the transfer system. The resilience here is defined as the ability to resist and recover from passenger flow fluctuation. In current typical studies, when analyzing system resilience, we first define (10) as the system service efficiency function. Based on the system efficiency function, the resilience function can be defined by the system efficiency rate $\left(C_{T} / C_{T 0}\right)$. The system resilience function can be expressed as

$$
R=\frac{\int\left(C_{T} / C_{T 0}\right) \mathrm{d} t}{T_{P}} .
$$


The optimization process is to get the maximum $R$.

3.2. Coordinated Operation. Slack-time cost includes passenger cost and vehicle cost. Specifically, it can be divided into three parts: The first term is the slack-time delay cost to passengers already on board. The second term is the waiting cost for passengers transferring to route $k$. The last term is the increased vehicle operating cost due to the slack time at each transfer station on route $k$. The slack-time cost can be expressed as

$$
C_{s}=\sum_{k} \sum_{m \in N(c)}\left(D_{m k} v+F_{m k} \mu+\frac{B_{k}}{h_{k}}\right) s_{m k} \delta_{m k} .
$$

The transfer waiting time should consider the difference in headways and slack times between two routes. In real cases, the passenger flows of different routes, and hence the optimized headways of those routes, may differ greatly. Therefore, this paper uses the Integer-Ratio Headways, introduced in [13]. In this case, the vehicle operating cost, passenger waiting cost, and in-vehicle cost are the same as for the uncoordinated operation. In [13] passenger waiting times are analyzed based on the condition that the headways as well as scheduled travel times between transfer stations are the same or integer multiples of the same cycle time. The waiting time is

$z_{j k}=\frac{g_{j k} y}{h_{k}} \sum_{i=1}^{\left(\left(h_{k} / g_{j k}\right)-1\right)}\left(i g_{j k} y+s_{m k}\right)=g_{j k} y\left(\frac{h_{k}}{2 g_{j k} y}-\frac{1}{2}\right)+s_{m k}$.

Thus, the transfer waiting times between connecting routes $j$ and $k$ are as follows:

$$
C_{p}=\sum_{j} \sum_{\substack{k \\ k \neq j}} \mu_{1} q_{j k} z_{j k} .
$$

Assuming reasonably that passengers may miss at most one bus, the missed-connection cost and delay-cost formulations are simplified. Since buses from both routes meet at the transfer station once every $h_{j} \times h_{k} /\left(g_{j k} \times y\right)$ minutes, the average transfer demand is $q_{j k} \times g_{j k} \times y / h_{k}$ for each connecting bus. The missed-connection cost is

$$
\begin{aligned}
C_{m}= & \sum_{m \in N(c)} \sum_{j} \sum_{k \neq j} \mu q_{j k} \frac{g_{j k} y}{h_{k}} \delta_{m k} \delta_{m j} \times\left[\int_{S_{m k}}^{h_{k}} \int_{-h_{k}}^{S_{m k}}\left(h_{k}-S_{m k}-t_{j}+S_{m j}\right) f\left(t_{k}\right) \mathrm{d} t_{k} f\left(t_{j}\right) \mathrm{d} t_{j}\right. \\
& \left.+\int_{S_{m j}}^{h_{j}} \int_{S_{m k}}^{t_{j}-S_{m j}+S_{m k}}\left(h_{k}-S_{m k}-t_{j}+S_{m j}\right) f\left(t_{k}\right) \mathrm{d} t_{k} f\left(t_{j}\right) \mathrm{d} t_{j}\right] .
\end{aligned}
$$

The dispatching-delay cost is

$$
\begin{aligned}
C_{d}= & \sum_{m \in N(c)} \sum_{j} \sum_{k \neq j} \mu q_{j k} \frac{g_{j k} y}{h_{k}} \delta_{m k} \delta_{m j} \times\left[\int_{S_{m k}}^{h_{k}} \int_{-h_{k}}^{S_{m k}}\left(t_{k}-S_{m k}\right) f\left(t_{k}\right) \mathrm{d} t_{k} f\left(t_{j}\right) \mathrm{d} t_{j}\right. \\
& \left.+\int_{S_{m j}}^{h_{j}} \int_{t_{j}-S_{m j}+S_{m k}}^{h_{k}}\left(t_{k}-S_{m k}-t_{j}+S_{m j}\right) f\left(t_{k}\right) \mathrm{d} t_{k} f\left(t_{j}\right) \mathrm{d} t_{j}\right] .
\end{aligned}
$$

The optimization procedure is specified as follows:

We first optimize the headway for each bus route separately.
We assume $T_{b}=0$ and $T_{\text {sig }}=0$. Since these two parameters are 0 , the total cost $C_{T}$ in our model will be the same as in [13]. 
The optimal headway of route $k$ can be obtained by setting the first derivative of the total cost with respect to headway $h_{k}$ to be zero and solving for $h_{k}$. The first derivative is

$$
\frac{\partial C_{T}}{\partial h_{k}}=-\frac{a_{k} T_{k}}{h_{k}^{2}}+\mu Q_{k}\left(\frac{1}{2}-\frac{\sigma_{k}^{2}}{2 h_{k}^{2}}\right)+\mu R_{k}\left(\frac{1}{2}-\frac{\sigma_{k}^{2}}{2 h_{k}^{2}}\right) .
$$

Thus, the optimal $h_{k}$ is

$$
h_{k}^{*}=\sqrt{\frac{2 a_{k} T_{k}+\mu \sigma_{k}^{2}\left(Q_{k}+R_{k}\right)}{\mu\left(Q_{k}+R_{k}\right)}} .
$$

The second derivative of total cost with respect to $h_{k}$ is

$$
\frac{\partial^{2} C_{T}}{\partial h_{k}^{2}}=\frac{2 a_{k} T_{k}}{h_{k}^{3}}+\frac{\mu R_{k} \sigma_{k}^{2}}{h_{k}^{3}}+\frac{\mu Q_{k} \sigma_{k}^{2}}{h_{k}^{3}} .
$$

Since each component in (19) is always positive, the second derivative is nonnegative, and thus $h_{k}^{*}$ globally minimizes the total system cost; then, the resilience is maximized.

The maximal headway (policy headway) permitted between two adjacent buses in route $k, h_{k}^{\max }=S_{k} l_{k} / Q_{k}$, must be checked for each route.

As in [13], the base cycle is optimized as a round fraction of $60 \mathrm{~min}$ (i.e., $60 \mathrm{~min}$ divided by an integer). For optimizing coordinated operations, the headways of different bus routes at the same transfer station should be optimized for multiples of the base cycle $y$. Based on that, slack time is set to minimize the expected total costs of bus operations and passenger waiting times, including those due to missed connections, which are affected by slack times.

Compared with the heuristic algorithm provided in [13], the optimizing goal and computational basis are changed here from system cost $\left(C_{T}\right)$ to system resilience $(R)$. Besides, more parameters are checked. We check $h_{k}^{*}$ to find if $T_{b}>0$ or $T_{\text {sig }}>0$. Since $T_{i}$ precludes signal priority, $T_{\text {sig }}$ should be 0 . We rank $\mathrm{T}_{b}$ in ascending order, reduce $h_{k}^{*}$ to reduce $\mathrm{T}_{b}$, update $\mathrm{T}_{k}$, and calculate $h_{k}^{*}$. This procedure is repeated until $N_{k}=0$ and no significant further improvement is obtained.

\section{Case Study}

4.1. Background of This Case. This paper focuses on a bus corridor which connects a rail transit station and includes multiple bus routes. It contains a rail transit station (Jiangsu Road Rail Transit Station, which is among the busiest in Shanghai) and a bus corridor (Yan'an Road transit corridor, which is the earliest established and largest transit corridor in Shanghai). We formulate a system resilience function and find the combinations of headways and slack times which maximize that function. There are two bus network configurations in this transit corridor, as shown in Figures 2 and 3. The pre-2017 network, in which there were three bus routes operating concurrently, is shown in Figure 2. After 2017 , route 71 serves as the main bus route in this corridor. It has been provided with exclusive bus lane and transit signal priority. First, analytical solutions for optimal headways in the uncoordinated transit network are found. Then, a heuristic algorithm is developed to jointly find the headways and slack times that maximize the system resilience for the coordinated transit network.

Yan'an Road bus lane starts at Zhongshan Road and ends at Gubei Road, with a total length of $10 \mathrm{~km}$. It opened in about 2000 as Shanghai's first bus lane. The section considered here extends from the West Yan'an Road-Kaixuan Road (KX) bus stop to the Mid Yan'an Road-Shimen Road No. 1 (SM) bus stop. Its characteristics are illustrated in Figures 1-3.

The data acquisition process uses an automated collection system and related equipment based on AVL, to gather GPS and smart card data. The bus routes have been changed in early 2017. Thus, our case study uses two data series: February to July in 2015 and February to July in 2018. The raw data includes the following data types:

Smart card data: card id, fare collection machine id, time point

Vehicle-route data: vehicle ID, route ID, route name

Bus stop data: stop ID, stop name, stop longitude, stop latitude

Route-stop data: route ID, route name, operating direction, stop number

GPS data: route ID, vehicle ID, time point, longitude, latitude, speed, direction angle

The baseline parameter values, adopted for the present work from "TCRP 165: Transit Capacity and Quality of Service Manual" [43] and field research by the Shanghai Science and Technology Committee (unpublished reports), are $B_{k}=4.0 \mathrm{RMB} /$ bus-min, $\mu_{1}=1.5 \mathrm{RMB} /$ passenger-min, $\mu_{2}=5.0 \mathrm{RMB} /$ passenger-min, $\mu_{3}=10,000 \mathrm{RMB} /$ passengermin, and $v=1.0 \mathrm{RMB} /$ passenger-min. In real networks, the travel times on each link between two hubs may differ considerably by period and travel direction. In this case, the travel direction is from suburban to urban area, and the time period is 6:00 am to $12: 00 \mathrm{pm}$.

In both conditions, we calculate the total cost by five methods: The first one is planned operation, which means we use the headways provided by the transit agency. In the second method, called uncoordinated operation, the headways are optimized independently for the different routes. In the coordinated operation, the headways and slack time of different routes are optimized jointly, using the method in [13], based on average passenger volume (method 3) and maximum passenger volume (method 4). The method proposed in this paper is presented as the fifth method, called the resilience optimized operation. In this method, the headways and slack times of different routes are optimized jointly, considering boarding delay and missed signal priority delay.

\subsection{General Comparison}

4.2.1. Initial (Pre-2017) Bus Routes. This corridor included three bus routes: 71, 127, and 936, as shown in Figure 1. The 


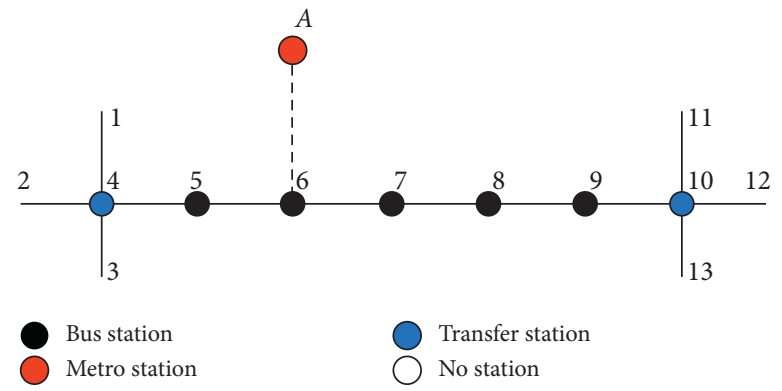

Figure 3: Modified bus routes layout.

TABLE 2: Comparison of different operation methods at average passenger flows.

\begin{tabular}{|c|c|c|c|c|c|}
\hline Variables & $\begin{array}{c}\text { Planned } \\
\text { operation }\end{array}$ & $\begin{array}{c}\text { Uncoordinated } \\
\text { operation }\end{array}$ & $\begin{array}{c}\text { Coordinated operation (avg. } \\
\text { passenger volume) }\end{array}$ & $\begin{array}{c}\text { Coordinated operation (max } \\
\text { passenger volume) }\end{array}$ & $\begin{array}{c}\text { Resilience optimized } \\
\text { operation }\end{array}$ \\
\hline$h_{a}$ & 3 & 3.051 & 4 & 3 & 4 \\
\hline$h_{b}$ & 10 & 9.887 & 12 & 9 & 8 \\
\hline$h_{c}$ & 30 & 28.169 & 28 & 27 & 28 \\
\hline$S_{3 a}$ & - & - & 1.00 & 1.00 & 1.00 \\
\hline$S_{3 b}$ & - & - & 2.00 & 1.00 & 2.00 \\
\hline$S_{3 c}$ & - & - & 2.00 & 2.00 & 2.00 \\
\hline$C_{o}$ & 137.096 & 144.316 & 146.316 & 151.373 & 148.387 \\
\hline$T_{b}$ & 17.212 & 10.143 & 6.562 & 0 & 0 \\
\hline$N_{71}$ & 0 & 0 & 0 & 0 & 0 \\
\hline$N_{127}$ & 0 & 0 & 0 & 0 & 0 \\
\hline$N_{936}$ & 0 & 0 & 0 & 0 & 0 \\
\hline$C_{w}$ & 166.537 & 135.103 & 131.004 & 128.143 & 129.097 \\
\hline$C_{N}$ & 303.633 & 279.419 & 277.320 & 279.516 & 277.320 \\
\hline$C_{p}$ & - & - & 5.136 & 5.193 & 5.198 \\
\hline$C_{s}^{p}$ & - & - & 7.184 & 7.091 & 7.077 \\
\hline$C_{m}$ & - & - & 11.213 & 11.392 & 11.432 \\
\hline$C_{d}$ & - & - & 3.123 & 3.431 & 3.308 \\
\hline$C_{f}^{a}$ & 30.151 & 28.193 & 26.656 & 27.107 & 26.656 \\
\hline$C_{T}$ & 333.784 & 307.612 & 303.976 & 306.623 & 304.499 \\
\hline$R$ & 0.916 & 0.930 & 0.948 & 0.942 & 0.964 \\
\hline
\end{tabular}

configuration of these bus routes is shown in Figure 2. Station ids $a 2$ to $a 7$ mean stations on route 71 , station id $b$ means stations on route 127 , and station id $c$ means stations on route 936 . Note that when $i=1$ to $7, a_{\mathrm{i}}, b_{\mathrm{i}}$, and $c_{\mathrm{i}}$ are the same station on different routes. However, $a 1, b 1, c 1, a 8, b 8$, and $c 8$ are different stations. The blank points $c 4, b 5$, and $c 6$ mean that there are no stations on these routes, and thus buses pass through without stopping.

The comparison of different operation methods is shown in Table 2.

Table 2 shows that all four optimizing methods increase the system resilience and reduce the total cost compared to the planned operation (method 1). The method proposed in this paper can increase the system resilience more than the other methods and does not increase the total cost (304.499 RMB compared with 306.623 RMB and 303.976 RMB). It performed well in real cases with real passenger volumes. Coordinated operation is preferable to uncoordinated operation. Its operation cost is higher than that of uncoordinated operation, but the waiting cost and transfer cost decrease more, so the total cost decreases, as shown in Table 2.

4.2.2. After Changing Bus Routes. Bus route 71 is the main route in this corridor. It operates on an exclusive lane and has signal priority. At stations 4 and 10, there are two feeder bus routes: route 1250 (marked as route $a$ ) at station 4 and route 974 (marked as route $b$ ). The configuration of these three bus routes is shown in Figure 3.

The comparative results for different operation methods after bus route restructuring are shown in Table 3 .

Table 3 shows that all the four optimizing methods increase the system resilience and reduce the total cost compared to the planned operation. Coordinated operation is preferable to uncoordinated operation. Its operation cost is higher than that of uncoordinated operation, but the waiting cost and transfer cost decrease more, so the total cost decreases. The table also shows that bus route 71 misses signal priority 5 times per hour when it operates as planned. All the optimized operations reduce the missing times, and 
TABLE 3: Comparison of different operation methods after restructuring routes.

\begin{tabular}{|c|c|c|c|c|c|}
\hline Variables & $\begin{array}{l}\text { Planned } \\
\text { operation }\end{array}$ & $\begin{array}{l}\text { Uncoordinated } \\
\text { operation }\end{array}$ & $\begin{array}{l}\text { Coordinated operation (avg. } \\
\text { passenger volume) }\end{array}$ & $\begin{array}{l}\text { Coordinated operation ( } \max \\
\text { passenger volume) }\end{array}$ & $\begin{array}{c}\text { Resilience optimized } \\
\text { operation }\end{array}$ \\
\hline$h_{a}$ & 4 & 3.801 & 4 & 3 & 4 \\
\hline$h_{b}$ & 11 & 11.150 & 12 & 9 & 8 \\
\hline$h_{c}$ & 15 & 14.731 & 16 & 12 & 16 \\
\hline$S_{4 a}$ & - & - & 0.50 & 1.00 & 0.50 \\
\hline$S_{4 b}$ & - & - & 1.00 & 0.50 & 1.00 \\
\hline$S_{10 a}^{40}$ & - & - & 1.00 & 0.50 & 0.50 \\
\hline$S_{10 c}$ & - & - & 1.00 & 1.00 & 1.00 \\
\hline$C_{o}$ & 157.116 & 162.210 & 170.310 & 171.310 & 171.145 \\
\hline$T_{b}$ & 16.211 & 11.312 & 7.143 & 0 & 0 \\
\hline$N_{71}$ & 5 & 3 & 2 & 0 & 0 \\
\hline$N_{127}$ & 0 & 0 & 0 & 0 & 0 \\
\hline$N_{936}$ & 0 & 0 & 0 & 0 & 0 \\
\hline$C_{w}$ & 173.342 & 158.332 & 149.433 & 148.707 & 149.067 \\
\hline$C_{N}$ & 330.458 & 320.542 & 319.743 & 320.017 & 320.212 \\
\hline$C_{p}$ & - & - & 5.973 & 6.854 & 6.104 \\
\hline$C_{s}^{P}$ & - & - & 6.985 & 7.013 & 6.847 \\
\hline$C_{m}$ & - & - & 12.211 & 12.610 & 12.146 \\
\hline$C_{d}$ & - & - & 4.016 & 4.123 & 4.073 \\
\hline$C_{f}$ & 36.131 & 31.631 & 29.185 & 30.600 & 29.170 \\
\hline$C_{T}^{J}$ & 366.589 & 352.173 & 348.928 & 350.617 & 349.382 \\
\hline$R$ & 0.874 & 0.921 & 0.944 & 0.939 & 0.957 \\
\hline
\end{tabular}

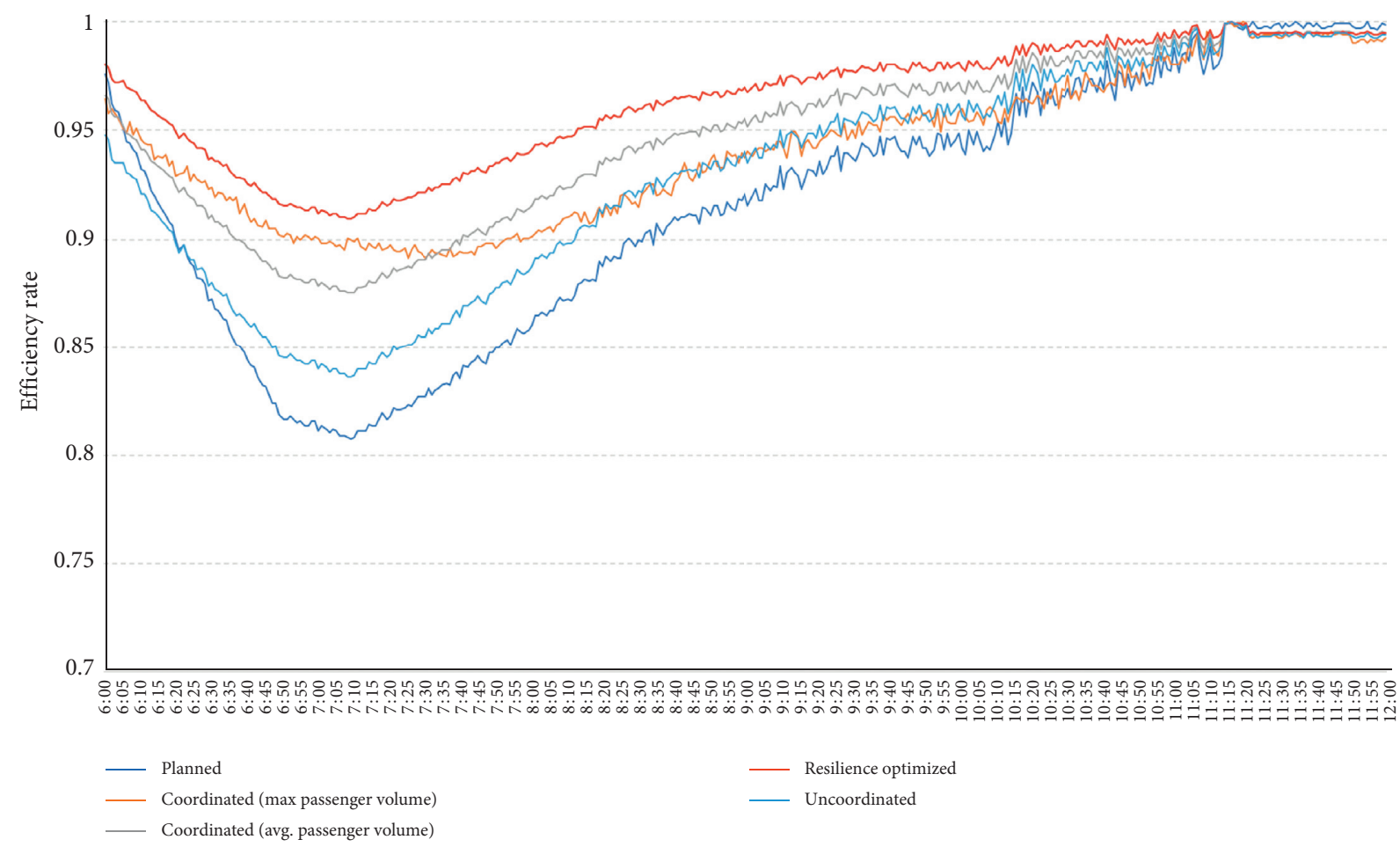

FIGURE 4: Detailed comparison of these optimization methods.

coordinated operations perform better: With the proposed method, the boarding delay and the hourly number of missed signal priorities become 0 ; the operation cost is lower than that of method four. All the optimized operations reduce the total cost; among them the coordinated operations perform better compared with the uncoordinated ones.
4.3. Detailed Comparison. To understand how these results arise, we take the results of initial bus routes to compare these five methods in detail within the whole time period. The comparison is based on the results in February to July 2018. The minute-based evaluation graph is shown below.

From Figure 4, we can understand the following: 
TABLE 4: Levels of system efficiency rate.

\begin{tabular}{lccccc}
\hline Level & $A$ & $B$ & $C$ & $D$ & $E$ \\
\hline Efficiency rate & $1-0.95$ & $0.95-0.90$ & $0.90-0.85$ & $0.85-0.80$ & $<0.80$ \\
\hline
\end{tabular}

Level A is the ideal level.

TABLe 5: Comparison of optimization methods based on levels of system efficiency rate.

\begin{tabular}{|c|c|c|c|c|c|}
\hline Variables & $\begin{array}{l}\text { Planned } \\
\text { operation }\end{array}$ & $\begin{array}{l}\text { Uncoordinated } \\
\text { operation }\end{array}$ & $\begin{array}{c}\text { Coordinated operation } \\
\text { (avg. passenger } \\
\text { volume) }\end{array}$ & $\begin{array}{c}\text { Coordinated operation } \\
\text { (max passenger } \\
\text { volume })\end{array}$ & $\begin{array}{c}\text { Resilience } \\
\text { optimized operation }\end{array}$ \\
\hline The lowest efficiency rate & $0.808(0.074)$ & $0.836(0.067)$ & $0.875(0.076)$ & $0.892(0.071)$ & $0.909(0.056)$ \\
\hline $\begin{array}{l}\text { Time for recovering to } \\
\text { level } A \text { (min) }\end{array}$ & $251(17)$ & $207(16)$ & $163(16)$ & $198(16)$ & $111(14)$ \\
\hline Level $A$ (min) & $109(11)$ & $153(13)$ & $197(13)$ & $162(12)$ & $249(10)$ \\
\hline Level $B$ (min) & $84(7)$ & $95(6)$ & $99(8)$ & $133(7)$ & $111(7)$ \\
\hline Level $C$ (min) & $94(7)$ & $75(7)$ & $64(5)$ & $65(5)$ & $0(0)$ \\
\hline Level $D$ (min) & $73(6)$ & $37(4)$ & $0(0)$ & $0(0)$ & $0(0)$ \\
\hline Level $E(\min )$ & $0(0)$ & $0(0)$ & $0(0)$ & $0(0)$ & $0(0)$ \\
\hline
\end{tabular}

Note. The variance is shown in the brackets.

(1) The efficiency rate $\left(C_{T} / C_{T 0}\right)$ decreases when morning peak period starts and increases when it ends. All these 5 methods can make the system recover from passenger volume increasing, since the efficiency rates of all these 5 methods increase to 1 finally.

(2) The planned method performs the worst. When passenger volume increases, the efficiency rate decreases and reaches a very low level.

(3) The uncoordinated method performs better than the planned method but worse than the coordinated methods.

(4) When we use the methods introduced by Ting and Schonfeld [13], the results differ based on different passenger volume. When we use average passenger volume, the efficiency decreases greatly since the headway is too long. At the maximum passenger volume, the operation cost is high even when passenger volume is not very high (before 6:30 am and after 9:30 am), so the efficiency rate recovers slowly.

(5) The proposed method performs best since it uses reasonable headways with realistic passenger volume.

According to "Transit Capacity and Quality of Service Manual" ( $3^{\text {rd }}$ edition) [43], the service quality can be divided into five levels. In this case, we can use this standard to divide the efficiency rate into five levels, which are shown in Table 4.

Then, we compare these 5 methods based on the results in Figure 4 and the results are shown in Table 5.

From Table 5, we can find that the proposed method not only resists the efficiency rate decrease but also has the shortest time for recovering to level $A$, so it has the highest resilience. Besides, among these methods, coordinated operation performs better than uncoordinated operation. Planned operation performs the worst. Coordinated operation avoids level $D$, and the proposed method avoids level $C$.

\section{Conclusions and Recommendations}

This paper proposed an extension of the schedule coordination method by Ting and Schonfeld [13] for jointly optimizing headways and slack times in coordinated schedules for public transportation routes within the aspect of resilience. This method is applied in a realistic case, with passenger flow fluctuations as well as travel time variability based on operating conditions. The main contributions are as follows.

Firstly, this paper applies and extends a schedule coordination model within a real multihub environment (stations 2-7 in Figure 2 and stations 4, 6, and 10 in Figure 3), considering passenger flow fluctuations and whether transit priority is provided, within the new resilience angle. This advance improves this method's practicality.

Secondly, the case study presented here shows that the coordinated schedule obtained with the proposed method can ensure high system resilience based on the verification with realistic passenger volumes, which means it performs well in resisting and recovering from passenger volume fluctuations and traffic variations. It balances the operation cost and passenger cost. The proposed method improves the resilience of the schedule.

Thirdly, this paper focuses on a transit corridor, combining data from several bus routes for analysis. It improves data volume and accuracy. This paper allows transit agencies to optimize coordinated schedules considering passenger flow fluctuations and transit priority.

Resilience is important in analyzing and optimizing transit schedules. The value of the resilient schedule coordination method proposed in this paper is demonstrated for balancing operator and user costs in real world, considering 
passenger flow fluctuations and traffic variations. Further research may not only consider more parameters in different environments, but also explore more efficient algorithms for solving this problem. Besides, this method can be further extended from corridors to urban transit networks, intercity trains, buses, and airlines.

\section{Data Availability}

The GPS and smart card data used to support the findings of this study are restricted by the Shanghai Science and Technology Committee. Requests for data will be considered by the corresponding author for researchers who meet the criteria for access to confidential data.

\section{Conflicts of Interest}

The authors declare that they have no conflicts of interest.

\section{Authors' Contributions}

Study conception and design were conducted by Xiongfei Lai, Jing Teng, and Paul Schonfeld. Data were collected by Xiongfei Lai and Jing Teng. Analysis and interpretation of results were performed by Xiongfei Lai. Manuscript draft was prepared by Xiongfei Lai Jing Teng, Paul Schonfeld, and Lu Ling. All authors reviewed the results and approved the final version of the manuscript.

\section{Acknowledgments}

This work was supported by "Public Transit System Simulation Analysis Platform and Demonstrations" (project no. 17DZ1204409), in the field of social development of "Science and Technology Innovation Action Plan," Shanghai Science and Technology Committee. It was also supported by the program of China Scholarships Council (no. 201806260146), College of Transportation Engineering, Key Laboratory of Road and Traffic Engineering of the State Ministry of Education, Shanghai Key Laboratory of Rail Infrastructure Durability and System Safety.

\section{References}

[1] M. H. Rapp and C. D. Gehner, "Transfer optimization in an interactive graphic system for transit planning," Transportation Research Record: Journal of the Transportation Research Board, vol. 619, pp. 27-33, 1976.

[2] K. K. T. Lee and P. Schonfeld, "Optimal slack time for timed transfers at a transit terminal," Journal of Advanced Transportation, vol. 25, no. 3, pp. 281-308, 1991.

[3] I. Andréasson, "Volvo approach to computer-aided transportation planning: Transportation research record," Journal of the Transportation Research Board, vol. 657, pp. 9-14, 1977.

[4] M. Abkowitz, R. Josef, J. Tozzi, and M. K. Driscoll, "Operational feasibility of timed transfer in transit systems," Journal of Transportation Engineering, vol. 113, no. 2, pp. 168-177, 1987.

[5] A. Désilets and J.-M. Rousseau, "SYNCRO: a computerassisted tool for the synchronization of transfers in public transit networks," in Computer-Aided Transit Scheduling, pp. 153-166, Springer, Berlin, Germany, 1992.

[6] C. Daganzo, "On the coordination of inbound and outbound schedules at transportation terminals," in Proceedings of the International Symposium on Transportation and Traffic Theory, Yokohama, Japan, July 1990.

[7] A. Ceder, B. Golany, and O. Tal, "Creating bus timetables with maximal synchronization," Transportation Research Part A: Policy and Practice, vol. 35, no. 10, pp. 913-928, 2001.

[8] A. Ceder and O. Tal, "Designing synchronization into bus timetables. Transportation research Record," Transportation Research Record: Journal of the Transportation Research Board, vol. 1760, no. 1, pp. 28-33, 2001.

[9] O. J. Ibarra-Rojas and Y. A. Rios-Solis, "Synchronization of bus timetabling," Transportation Research Part B: Methodological, vol. 46, no. 5, pp. 599-614, 2012.

[10] L. Zhigang, S. Jinsheng, W. Haixing, and W. Yang, "Regional bus timetabling model with synchronization," Journal of Transportation Systems Engineering and Information Technology, vol. 7, no. 2, pp. 109-112, 2007.

[11] J. H. Bookbinder and A. Désilets, "Transfer optimization in a transit network," Transportation Science, vol. 26, no. 2, pp. 106-118, 1992.

[12] A. Ceder, Public Transit Planning and Operation: Theory, Modeling and Practice, Elsevier, Butterworth-Heinemann, Amsterdam, Netherlands, 2007.

[13] C.-J. Ting and P. Schonfeld, "Schedule coordination in a multiple hub transit network," Journal of Urban Planning and Development, vol. 131, no. 2, pp. 112-124, 2005.

[14] O. J. Ibarra-Rojas, F. Delgado, R. Giesen, and J. C. Muñoz, "Planning, operation, and control of bus transport systems: a literature review," Transportation Research Part B: Methodological, vol. 77, pp. 38-75, 2015.

[15] M. Wei and B. Sun, "Bi-level programming model for multimodal regional bus timetable and vehicle dispatch with stochastic travel time," Cluster Computing, vol. 20, no. 1, pp. 401-411, 2017.

[16] B. Varga, T. Tettamanti, and B. Kulcsár, "Optimally combined headway and timetable reliable public transport system," Transportation Research Part C: Emerging Technologies, vol. 92, pp. 1-26, 2018.

[17] T. Liu and A. Ceder, "Integrated public transport timetable synchronization and vehicle scheduling with demand assignment: a bi-objective bi-level model using deficit function approach," Transportation Research Procedia, vol. 23, pp. 341-361, 2017.

[18] Y. Wu, H. Yang, J. Tang, and Y. Yu, "Multi-objective resynchronizing of bus timetable: model, complexity and solution," Transportation Research Part C: Emerging Technologies, vol. 67, pp. 149-168, 2016.

[19] S. J. Berrebi, K. E. Watkins, and J. A. Laval, "A real-time bus dispatching policy to minimize passenger wait on a high frequency route," Transportation Research Part B: Methodological, vol. 81, pp. 377-389, 2015.

[20] Y. Xuan, J. Argote, and C. F. Daganzo, "Dynamic bus holding strategies for schedule reliability: optimal linear control and performance analysis," Transportation Research Part B: Methodological, vol. 45, no. 10, pp. 1831-1845, 2011.

[21] J. Wu, M. Liu, H. Sun, T. Li, Z. Gao, and D. Z. W. Wang, "Equity-based timetable synchronization optimization in urban subway network," Transportation Research Part C: Emerging Technologies, vol. 51, pp. 1-18, 2015.

[22] L. Kang, J. Wu, H. Sun, X. Zhu, and Z. Gao, "A case study on the coordination of last trains for the Beijing subway 
network," Transportation Research Part B: Methodological, vol. 72, pp. 112-127, 2015.

[23] I. Dakic, L. Ambühl, O. Schümperlin, and M. Menendez, "On the modeling of passenger mobility for stochastic bi-modal urban corridors," Transportation Research Part C: Emerging Technologies, vol. 113, pp. 146-163, 2020.

[24] F. Castrillon and J. Laval, "Impact of buses on the macroscopic fundamental diagram of homogeneous arterial corridors," Transportmetrica B: Transport Dynamics, vol. 6, no. 4, pp. 286-301, 2018.

[25] K. Arnet, S. I. Guler, and M. Menendez, "Effects of multimodal operations on urban roadways. Transportation research Record," Transportation Research Record: Journal of the Transportation Research Board, vol. 2533, no. 1, pp. 1-7, 2015.

[26] O. J. Ibarra-Rojas, F. López-Irarragorri, and Y. A. Rios-Solis, "Multiperiod Bus Timetabling," Transportation Science, vol. 50, no. 3, pp. 805-822, 2015.

[27] M. Kim and P. Schonfeld, "Integrating bus services with mixed fleets," Transportation Research Part B: Methodological, vol. 55, pp. 227-244, 2013.

[28] M. Kim and P. Schonfeld, "Integration of conventional and flexible bus services with timed transfers," Transportation Research Part B: Methodological, vol. 68, pp. 76-97, 2014.

[29] S. I.-J. Chien, Y. Ding, and C. Wei, "Dynamic bus arrival time prediction with artificial neural networks," Journal of Transportation Engineering, vol. 128, no. 5, pp. 429-438, 2002.

[30] R. Jeong and R. Rilett, "Bus arrival time prediction using artificial neural network model," in Proceedings of the 7th International IEEE Conference on Intelligent Transportation Systems (IEEE Cat. No. 04TH8749), pp. 988-993, IEEE, Washington, WA, USA, October 2004.

[31] Homeland Security Advisory Council, "Report of the critical infrastructure task force," 2006, http://www.dhs.gov/xlibrary/ assets/HSAC_CITF_Report_v2.pdf.

[32] A. Rose and S.-Y. Liao, "Modeling regional economic resilience to disasters: a computable general equilibrium analysis of water service disruptions," Journal of Regional Science, vol. 45, no. 1, pp. 75-112, 2005.

[33] E. D. Vugrin, D. E. Warren, M. A. Ehlen et al., "A framework for assessing the resilience of infrastructure and economic systems," in Sustainable and Resilient Critical Infrastructure Systems, pp. 77-116, Springer, Berlin, Germany, 2010.

[34] R. Dorbritz, Assessing the Resilience of Transportation Systems in Case of Large-Scale Disastrous Events, Vilnius Gediminas Technical University Press Technika, Vilnius, Lithuania, 2011.

[35] R. Li, Q. Dong, C. Jin, and R. Kang, "A new resilience measure for supply chain networks," Sustainability, vol. 9, no. 1, p. 144, 2017.

[36] H. Wakabayashi and Y. Iida, "Upper and lower bounds of the terminal reliability of road networks: an efficient method with Boolean algebra," Journal of Natural Disaster Science, vol. 14, no. 1, pp. 29-44, 1992.

[37] S. Havlin, "Robustness of a network of networks," Physical Review Letters, vol. 107, no. 19, Article ID 195701, 2010.

[38] J. Bates, J. Polak, P. Jones, and A. Cook, "The valuation of reliability for personal travel," Transportation Research Part E: Logistics and Transportation Review, vol. 37, no. 2-3, pp. 191-229, 2001.

[39] Y. Asakura, "Reliability measures of an origin and destination pair in a deteriorated road network with variable flows," in Proceedings of the Fourth Meeting of the EURO Working Group in Transportation, Tyne, UK, September 1996.

[40] Y. Zhu, K. Ozbay, K. Xie, and H. Yang, "Using big data to study resilience of taxi and subway trips for Hurricanes Sandy and Irene," Transportation Research Record: Journal of the Transportation Research Board, vol. 2599, no. 1, pp. 70-80, 2016.

[41] O. Cats and E. Jenelius, "Dynamic vulnerability analysis of public transport networks: mitigation effects of real-time information," Networks \& Spatial Economics, vol. 14, no. 3-4, pp. 435-463, 2014.

[42] D. Watling and N. C. Balijepalli, "A method to assess demand growth vulnerability of travel times on road network links," ransportation Research Part A: Policy and Practice, vol. 46, no. 5, pp. 772-789, 2012.

[43] Transportation Research Board, Transit Capacity and Quality of Service Manual, Transportation Research Board, Washington, DC, USA, 3rd edition, 2013.

[44] W. Fan and Z. Gurmu, "Dynamic travel time prediction models for buses using only GPS data," International Journal of Transportation Science and Technology, vol. 4, no. 4, pp. 353-366, 2015.

[45] J. Teng and X. Lai, "An integrated method for urban transit evaluation and optimization," Advances in Mechanical Engineering, vol. 9, no. 7, 2017.

[46] J. O. Jansson, "A simple bus line model for optimisation of service frequency and bus size," Journal of Transport Economics and Policy, vol. 14, no. 1, pp. 53-80, 1980.

[47] P. I. Welding, "The instability of a close-interval service," Journal of the Operational Research Society, vol. 8, no. 3, pp. 133-142, 1957.

[48] E. E. Osuna and G. F. Newell, "Control strategies for an idealized public transportation system," Transportation Science, vol. 6, no. 1, pp. 52-72, 1972. 